\title{
Reading Comprehension and Second Language Devel- opment in a Comprehension-Based ESL Program ${ }^{12}$
}

T. Sima Paribakht and Marjorie Bingham Wesche

The paper reports on an exploratory study of the acquisition of specific content vocabulary, discourse connectives and grammatical knowledge over time by instructed adult L2 learners. A major objective of the study was the development of an appropriate methodology and instruments for classroom research on these questions.

The study followed 37 intermediate level ESL students through one semester, including one class in a themebased program centered on comprehension activities, and a comparison class in a four-skill program.

Findings are reported and discussed in terms of the methodology and instruments developed and adapted for the study, and of learning outcomes for the two groups. The instruments proved to be largely appropriate for our purposes. The findings indicate that gains on grammatical knowledge measures were somewhat greater for the four-skill class, while the comprehension-based demonstrated greater gains in vocabulary knowledge (both discourse connectives and content words).

\section{INTRODUCTION}

This paper reports on the first stage of a long-term project to investigate the role of comprehension in second language development by young adults. The context is a comprehensionbased program for beginning to intermediate learners of English as a second language. Our objective is to study the language learning outcomes of a teaching approach which emphasizes global comprehension of written and oral texts. These outcomes include gains in vocabulary, grammatical and discourse knowledge. In this context we have focused on vocabulary learning outcomes from written texts used for global reading comprehension and related activities. Our immediate concern, however, has been the development of an appropriate methodology for beginning to investigate these relationships. We will discuss our findings from an exploratory study carried out in the fall of 1989.

\section{THEORETICAL BACKGROUND}

A widely held view in the current literature on second language acquisition is that one major way in which second language learners acquire grammatical and other kinds of language knowledge is through exposure to and comprehension of the meaning of oral and written texts in that language. Considerable research has been done on the nature of language input to second language learners 
(cf. review in Hatch, 1983; Chaudron, 1988a; Larsen-Freeman \& Long, 1991; Wesche, forthcoming). Particular attention has been given to modifications made by native speakers addressing language learners, which are thought to increase the comprehensibility of the input and possibly to facilitate their language acquisition in several ways. Some studies have examined the effect of input modifications on the comprehensibility of spoken discourse by native speakers (e.g., Henzl, 1973; Long, 1985; Chaudron, 1985, 1988). Other research has linked such modifications to global proficiency gains (e.g., Edwards, Wesche, Krashen, Clement \& Kruidenier, 1984; Wesche \& Ready, 1985), and in some cases to the acquisition of specific elements of syntax and vocabulary (e.g., Wagner-Gough \& Hatch, 1975; Lightbown, 1983; Hawkins, 1987; Braidi, 1990). While links between input features and acquisition have been demonstrated to some extent, there remains a need for research on the relationship between the act of comprehension and the internalization of linguistic knowledge (Faerch \& Kasper, 1986; Long, 1983). Recent work by Ellis (1992) on a methodology for investigating the acquisition of syntactic knowledge through meaning-focused comprehension activities, using manipulated language, is one of few examples of the latter.

\section{COMPREHENSION-BASED INSTRUCTION}

\section{Theoretical rationale}

The theoretical rationale for a comprehension-based approach at early stages of teaching second languages came initially from studies of first language acquisition, in which the development of listening comprehension ability precedes and underlies the development of speaking ability, and later, in school, fluent reading of age appropriate texts precedes and facilitates the development of L1 composition skills. Further support for a comprehension-based approach to second language teaching has come from empirical research (Postovsky, 1974; see reviews in Krashen, 1981, 1985; Lightbown, 1992). An initial second language "incubation" or "internalization" period, where learners concentrate on understanding the meanings of oral and written texts, is thought to help them to "formulate a map of meaning and form in their minds and to internalize the associations between form and meaning" (Swaffar, 1986, p. 9). If learners are allowed to focus on language as a vehicle for meaning, it is thought that they will gradually assimilate syntactic and vocabulary knowledge in the target language. This receptive knowledge will form the basis for the production of utterances in the language. Some researchers go so far as to claim 
that production skills will "emerge" without explicit practice, as students receive and internalize large quantities of comprehended input (Krashen, 1985; Swaffar \& Stephens, 1981). Requiring learners to produce in early stages is seen as not only frustrating and anxiety-causing for them, but also as counterproductive to an efficient learning process (Postovsky, 1974; Terrell, 1982). It is thought that forcing production in the absence of adequate language knowledge causes students to fall back on first language knowledge, leading to the L1 and L2 "transfer" phenomena observed in their speech and writing (Newmark, 1966), and possibly even to the fossilization of inaccurate forms (Krashen, 1985).

Following this rationale, instruction in the comprehension-based approach begins with a period during which the learner is required only to comprehend written and oral texts, and not to produce them -although production is encouraged. The incubation period in the comprehension-based approach is claimed to result in more accurate production, as learners are given sufficient exposure to native speaker models and enough time to internalize accurate oral and written representations of the forms and structures of the target language. Empirical evidence has demonstrated that extensive listening before production results in more accurate pronunciation (Neufeld \& Schneiderman, 1980; Postovsky, 1981). Less is known about the effect of early emphasis on comprehension in the development of grammatical, vocabulary and discourse level knowledge. Krashen (1985) suggests that second language grammar is acquired through the understanding of meaning and that initial emphasis on formal aspects of language is counterproductive; formal knowledge is acquired incidentally while the learner is focused on meaning. There is considerable empirical evidence from Canadian French immersion programs and other contexts where comprehension is emphasized almost exclusively in the initial stages that such development indeed takes place (Edwards et al., 1984; Genesee, 1987; Harley, 1986, 1992; Lightbown, 1992; Swain \& Lapkin, 1982).

Recent research, including that with French immersion students, suggests, however, that learner analysis of language form as an aid in comprehending and creating texts may be important in developing grammatical accuracy in some aspects of speaking and writing-notably those that lack salience in communicative language use (Allen, Carroll, Burtis \& Gandino, 1987; Burger, 1989; Harley, 1992; Swain, 1985, 1988; Van Patten, 1990) and may even enhance comprehension ability (Courchêne \& Pugh, 1986; Champagne, research in progress). Proponents argue that learners need to know how formal structures organize and represent meaning, and that 
learners should therefore be made explicitly aware of the links between grammatical structure and meaning in oral and written input.

The ESL programs of the Second Language Institute (SLI) at the University of Ottawa offer the possibility of studying the effect of meaning-focused comprehension-based instruction on second language development and, as well, to contrast this with the effect of explicit form-focused instruction at similar proficiency levels. The initial research has explored both issues.

\section{Instructional Context and Procedures}

At the University of Ottawa, a large bilingual (French-English) university in Canada's national capital, undergraduate students are required to reach a certain level of listening and reading proficiency in their second language before graduation. In response to these institutional needs of students, the SLI has developed a comprehension-based program comprising four one-semester courses, drawing on the theoretical and empirical bases outlined above. The courses, given in both English and French for beginning and intermediate students, emphasize comprehension of oral and written texts throughout. The program content is thematically organized. The themes are carefully selected for their interest and appropriateness for university students, their current topicality, the availability of material and their potential for exploitation in the classroom. A variety of authentic written and oral teaching materials are used as the basis for comprehension questions, as well as for practice of specific reading and listening related skills (e.g., identifying the main idea, scanning, inferencing). There is no systematic teaching of grammar in these courses, although the grammatical questions and problems which arise are dealt with by teachers in context. Oral and written production in the second language is not required, but is encouraged as the students progress so that by the end of the second or early in their third semester students may frequently speak or write in class. They are not evaluated on this, however. The parallel existence of four-skill courses with explicit grammar instruction for other clienteles at the same proficiency levels at the University offers the possibility of comparative study of language development in the two instructional contexts.

\section{RESEARCH ISSUES \\ Methodological Questions}

The methodological issues dealt with in the study were the following: 
- What kinds of measurement instruments and procedures can be used to track student gains in specific aspects of target language proficiency (e.g., vocabulary, syntax, discourse markers)?

- Can a reliable self-report scale be developed which captures different levels of knowledge of vocabulary items?

- Can introspection be used as a technique for exploring how students deal with unknown vocabulary items while carrying out comprehension-based tasks?

\section{Research Questions}

The research questions dealt with in the study were the following:

- Do students make measurable gains in vocabulary and grammar knowledge in comprehension-based classes?

- Which type of vocabulary items are most easily acquired: content words (nouns, verbs, adjectives) or discourse connectives?

- Are content vocabulary items which are related to instructed themes more readily acquired than those taken from uninstructed themes?

- Can different stages of acquisition of vocabulary items be identified?

- Is grammatical knowledge acquired in comprehension-based courses without explicit grammatical instruction?

- How do the results from a comprehension-based course differ from those from a four-skill course at the same level?

\section{METHODOLOGY}

\section{Subjects}

Subjects were 37 young adult university students (19 in the Comprehension-based class and 18 in the Four-skill comparison class) from a mixture of first language backgrounds ${ }^{3}$. Both groups included a range of intermediate proficiency levels. The Placement Test for the Comprehension-based group, measuring reading and listening comprehension, was also administered to the Four-skill group to compare proficiency levels on receptive skills. The two groups did not differ significantly on this measure 4 .

\section{Classroom Treatment}

Both one-semester classes included 54 contact hours (four hours per week). The Comprehension-based class focused on the development of listening and reading skills using authentic texts (e.g., radio, newspaper) on selected themes. There was no systematic gram- 
matical instruction. Approximately $1 \frac{1 / 2}{2}$ hours were spent on instruction and practice of reading skills (e.g., scanning, skimming, guessing meaning in context, recognition of paragraph patterns) and reading authentic texts and answering comprehension questions on their content. Another $1 \frac{1}{2}$ hour period was reserved for comprehension practice in the language laboratory, during which students would listen to a recorded text or watch a video recording on the same theme as the current reading text and would then answer a series of questions focusing on different aspects of comprehension (global, specific information, inferencing). One hour per week was spent on newspaper or magazine reading and further development of reading skills with these texts.

The Four-skill class was taught using an integrated four-skill approach with $1 \frac{1}{2}$ hours a week devoted to grammar instruction, including explicit exercises on prepositions and vocabulary. Themebased listening and reading materials, including two themes which were also taught in the Comprehension-based class, were used for up to $1 \frac{1}{2}$ hours a week. A further $1 / 2$ hour a week was devoted to writing activities and at least that much time to speaking activities. Thus this class differed from the other both in its explicit grammar instruction and in the importance given to oral and written production.

\section{Measures}

The measurement instruments for this study were all based on written texts or sentences. The following measurement instruments and tasks were selected or developed for the study. All instruments were administered to both groups in class at the beginning and end of the course, with the exception of the Introspection Task, which was administered in the middle of the semester, and only to the Comprehension-based group.

\section{VOCABULARY MEASURES}

Three themes were selected as a basis for instrument development, according to the criteria discussed above. One of the themes, Media, was used for instructional units in both the Comprehensionbased and the Four-skill classes. A second theme, Family Custody, was used for instruction and introspective data gathering in the Comprehension-based class, and a third theme, Fitness, was retained for comparison testing (i.e., to measure student progress with materials not related to instruction).

A number of theme-related content words (nouns, verbs, adjectives) and cohesive markers (e.g., "in fact", "moreover", 
"however"), were selected from each written text. These items were then screened for French cognates with the help of a bilingual native speaker of French, since it is known that cognates present special learning characteristics and are generally easy for students in our bilingual context (Duquette, 1991). Based on the selected items, two sets of instruments were then developed to measure vocabulary acquisition as follows.

\section{Cloze Tests}

Two rational deletion Cloze Tests with approximately 35 blanks each were developed. These were created from theme-related written texts selected for the study (i.e., Media and Fitness), and tested the selected content words and cohesive markers. Students were asked to fill in the blanks from a master list which included all the missing words plus five distractors. The original (unmutilated) media text was presented in class as part of the theme unit on media, to develop comprehension skills and to provide general informational background.

\section{Vocabulary Knowledge Scale}

A self-report Vocabulary Knowledge Scale (VKS) was developed for the study (see Figure 1). This five-level description Vocabulary Knowledge Scale represented an attempt to capture different levels of self-perceived knowledge of specific words. These levels range from total unfamiliarity through recognition of the written word and some idea of its meaning, to the ability to use the word in a sentence.

\section{FIGURE 1}

\section{Vocabulary Knowledge Scale}

I. I have never scen this word.

II. I have seen this word before, but I don't know what it means.

III. I have seen this word before, and I think it means . (synonym or translation)

IV. I know this word. It means

V. I can use this word in a sentence: - (synonym or translation)

Students were administered each of the three theme-related wordlists in the VKS format on separate occasions. (Listed words were presented in scrambled order to remove contextual information.) Students were asked to indicate on the VKS their degree of 
knowledge of each target word. The VKS lists were administered prior to students' taking the corresponding cloze test.

\section{VKS Scoring}

The student self-report of vocabulary knowledge in categories III$\mathrm{V}$ on the VKS was used as evidence of demonstrated rather than perceived knowledge. Scoring adjustments were thus made to two self-reported categories, resulting in a 6-level scale. In category III, if the synonym or translation given was clearly wrong, the response was scored as category II; if correct, it was scored as category IV. Thus category III was important for eliciting perceptions and evidence of vocabulary knowledge for two different scoring categories. It was also retained for those few cases where it was impossible to judge whether students knew the target word or not.

It was necessary to split category $\mathrm{V}$ into two levels, to reflect both semantic knowledge and grammatical exactness of the use of the target word in a sentence context. If the word was mis-used according to both criteria, it was scored as category II. A category $\mathrm{V}$ score reflected knowledge of the referential meaning of the target word only. An example for the target word "chemicals" was: "Hydro Quebec produce some dangerous chemicals liquid with electricity." An example for "to retire" was "This famous player announce his retire." Other grammatical problems in formation of the sentence were ignored. Scoring category VI reflected both semantically and grammatically correct use of the target word in a sentence.

\section{GRAMMAR TESTS}

Two measures of grammatical knowledge were used in the study. The first, a test of grammatical knowledge developed by Bialystok and her colleagues (1981), consisted of five correct and twenty incorrect sentences (the latter with errors of tense, number, word order, etc.). Students were given scores for two levels of grammatical knowledge: 1) grammaticality judgements (recognition of correct and incorrect sentences); and 2) for their ability to correct the incorrect sentences 5 .

The second test measured knowledge of common Prepositions (i.e., at, on, to, with, in, of, for). In this test students were required to fill in missing prepositions in twenty sentences ${ }^{6}$. Scores were based on the number of correct prepositions provided.

\section{INTROSPECTION TASK}

Further data was gathered on vocabulary acquisition in the Comprehension-based class. A retyped newspaper text on the 
theme of Family Custody was given in class as a pre-test for vocabulary knowledge. Students were asked to read the text rapidly and to underline all words whose meanings they didn't know. The students were given another copy of the text, this time divided into segments of several sentences each. They were asked to read the text again and to answer six comprehension and four inferencing questions. While doing this, they were asked to write (in the spaces between segments) how they dealt with each unfamiliar word they had identified (e.g., ignored it, tried to infer the meaning, looked it up). A few days later, each student was given the list of words he or she had identified as unknown, together with the Vocabulary Knowledge Scale, and asked to indicate his or her level of knowledge of each word. The data collected included scores for the reading comprehension exercise, the questionnaires and the comments. The introspective data was gathered only in the Comprehension-based class, during the 8th week of a 13-week semester.

\section{ANALYSES}

The statistical analyses included calculation of:

- frequency data for VKS variables;

- descriptive statistics on all variables;

- analyses of covariance for all uncorrelated pre-post variables, using pre-test scores as covariates, to determine whether there were within-group gains or between-group differences. Paired t-tests were then used to locate within-group gains in cases where Ancova showed significant differences;

- multivariate repeated measures analysis for the correlated grammar measures to determine whether there were withingroup gains and/or between-group differences, or any interactions.

Frequency data were calculated on the VKS for all words, to determine the levels of vocabulary knowledge demonstrated by each individual for each item at the beginning and end of the course. They were also separately calculated for discourse connectives versus content words. Finally, to allow multivariate repeated measures analysis of vocabulary gains, the pre-post status of each word on the VKS was scored dichotomously. To do this, Vocabulary Knowledge Scale categories I, II and III (levels of relative familiarity with words for which the correct meaning is not known) were grouped into a "not known" category, and categories IV, V and VI (levels of knowledge of word meaning and correct use), were grouped into a "known" category. Scores were calculated for each student on the 
total number of "known" words at the beginning and end of the course, as well as for content words and discourse connectives. Ancova analyses and t-tests to pin point pre-post gains were done on these ("known"/"not known") scores.

\section{METHODOLOGICAL OUTCOMES AND LIMITATIONS}

With respect to methodology, the measures we used in our initial study proved largely appropriate for the intermediate proficiency level of our subjects and for our research purposes. All measures are sensitive enough to reflect specific gains on different aspects of language knowledge and use, but certain refinements are required. These are discussed below with respect to each instrument.

\section{Vocabulary Knowledge Scale ${ }^{7}$}

Students appeared to answer the VKS with certainty, and the patterns of change in vocabulary knowledge of the target words during their courses indicated that it captures progression in development of vocabulary knowledge. There appeared to be some variation in student interpretation of "I think" and "I know" (categories III and IV). Also, words were sometimes used in general ways in category $\mathrm{V}$ sentences which made it difficult to judge whether or not students knew a specific meaning of the word. To correct these problems we have clarified the instructions for the VKS by emphasizing the key instruction words, and now require that students writing a sentence for category $\mathrm{V}$ also provide a meaning in category IV.

The validity of the VKS also needs to be fully examined; however, this is difficult given the lack of theoretical consensus about the process of L2 vocabulary development and dearth of vocabulary instruments which aim to measure growth in knowledge of individual words (Curtis, 1987). In any case, we will carry out a concurrent validity study with a general proficiency measure and with a measure of vocabulary breadth with the independent sample.

It was necessary to merge the VKS categories into two major categories ("known" and "unknown" words) for quantitative analysis, as gains between adjacent categories (suggested by the descriptive statistics, Figure 2) could not be demonstrated statistically with this sample size. This can best be remedied through a much larger sample.

\section{Cloze Tests}

The cloze tests presented a number of problems, both theoretical and logistical. While it is not clear exactly which aspects of 
language knowledge are tapped by cloze tests, vocabulary knowledge clearly plays a major role. Cloze also provides the possibility of measuring knowledge of discourse connectives in extended texts. Thus the technique in our view added a dimension of information to vocabulary assessment not available through other measures. Part of our intended analysis was to compare cloze results with those of the VKS in terms of patterns of response on given word classes and relative difficulty levels. By creating rational cloze tests in which the blanks represented key vocabulary, and by providing a list of possible answers, we sought to focus students on the task of vocabulary recognition in context. We used reading texts appropriate for intermediate level students to construct the cloze tests. These tended to yield cloze tests which were too difficult for this level due to the reduced redundancy. The use of a word list made the task more time consuming than an open cloze, although it facilitated reliable scoring. A multiple choice format, with distractors based on errors made by similar groups of students, might have provided an alternative solution and an easier task. Since the time requirements of these tests made it impossible to administer all of them during class hours, only partial cloze data could be collected for the Four-skill group.

\section{Grammar Tests}

The difficulty level of the preposition test appeared to be appropriate, as both groups demonstrated pre-post gains (see below).

The grammar test proved inadequate for our purposes. Its results were puzzling in that no gains were demonstrated on the recognition of correct/incorrect sentences (presumably the easier task) even though there was no evidence of a ceiling effect. Gains were demonstrated on the more difficult correction task by one group however (Table 1).

\section{Introspection Task}

The introspection task yielded interesting information on what students attend to. It appears to us that some training of students to analyze and discuss their learning processes would be helpful. The introspection exercise in this study involved written comments. Recorded oral protocols should also be useful. These could be done in the mother tongue, ideally in a format that would allow interaction between researchers and learner. 


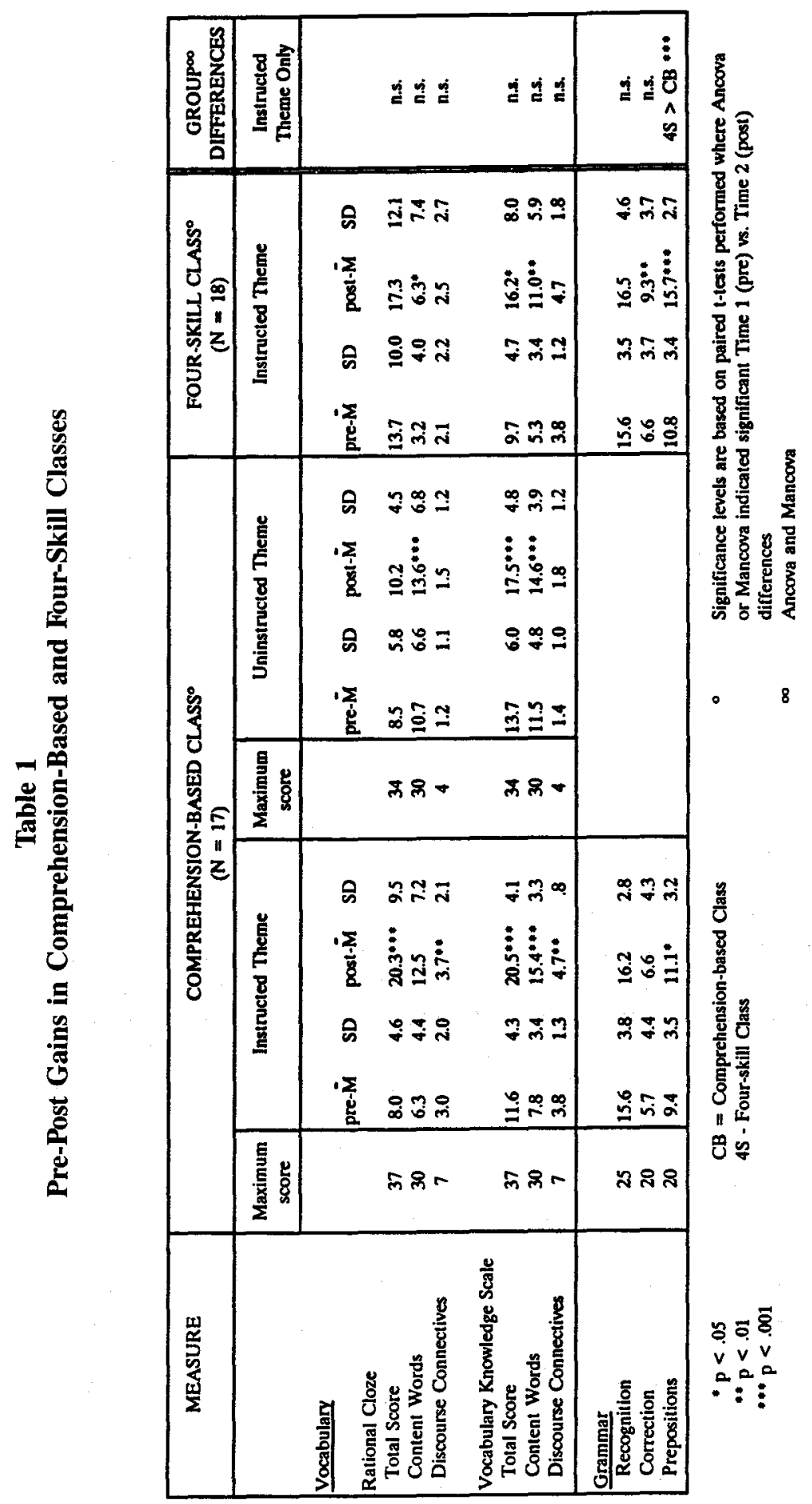




\section{RESEARCH FINDINGS}

Table 1 and Figure 2 present the following in summary form:

- descriptive statistics on each variable for all subjects having pre-test and post-test scores;

- summary results of Ancova analyses (for cloze, VKS and preposition scores) and Mancova analysis (for grammar measures) of differences in gains between the Comprehensionbased and Four-skill classes;

- T-tests showing the location and statistical significance of within-group pre-post gains;

- bar graphs illustrating pre-post scores on the VKS.

These are discussed below.

\section{Vocabulary}

Both classes showed gains on some vocabulary measures, revealing somewhat different patterns on the Cloze Tests and VKS favouring the Comprehension-based class. There were also differences in gains between content words and discourse connectives, the former in general being far easier, and, as one might expect, better learned when part of thematic class instruction. On the VKS wordlists for the instructed theme, a comparison of pre- and post-course results showed gains for both classes (total score and content word score). However, only the Comprehension-based class showed significant gains on discourse connectives. On the uninstructed theme, for which data were available only for the Comprehension-based class, VKS gains were significant for the total score and content words but not for discourse connectives. These results are illustrated graphically on Figure 2 and reflect shifts from scoring categories I-III (word not known) to categories IV-VI (word known) on the subscores for this scale. While it was impossible to statistically verify progress of students on individual words from one scale category to another due to the relatively small number of subjects and large numbers of words, the bar graphs indicate that such progress was made.

The Comprehension-based class made highly significant gains on the instructed cloze test (Media) on measures of total "known"words words, content words and discourse connectives, while on the uninstructed cloze test (Fitness) gains were only significant for content words. The Four-skill class, on the other hand, made significant gains only on the content words on the instructed cloze test. (Unfortunately the data for this class on the uninstructed theme were not valid due to the procedural problems mentioned earlier.) 
FIGURE 2

Pre-Post Changes, Vocabulary Knowledge Categories

Comprehension-Based Class

Media (Instructed)
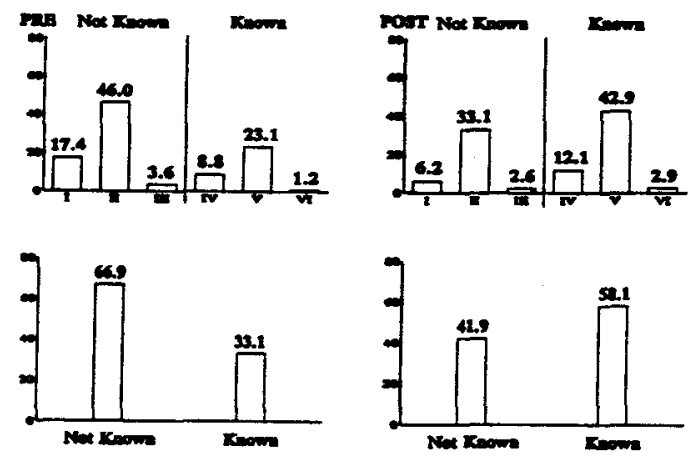

Finness (Uninstructed)
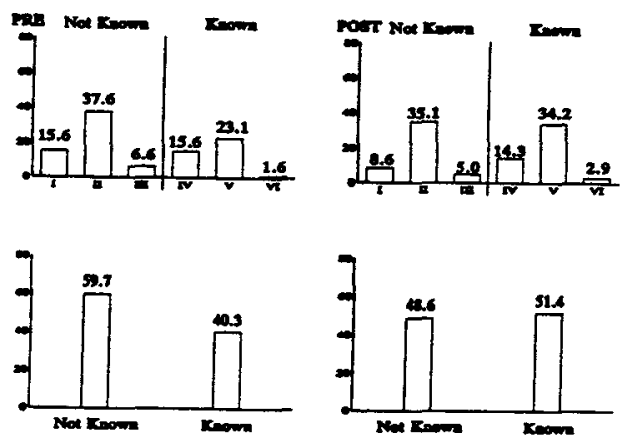

Four-Skill Class

Media (Instructed)
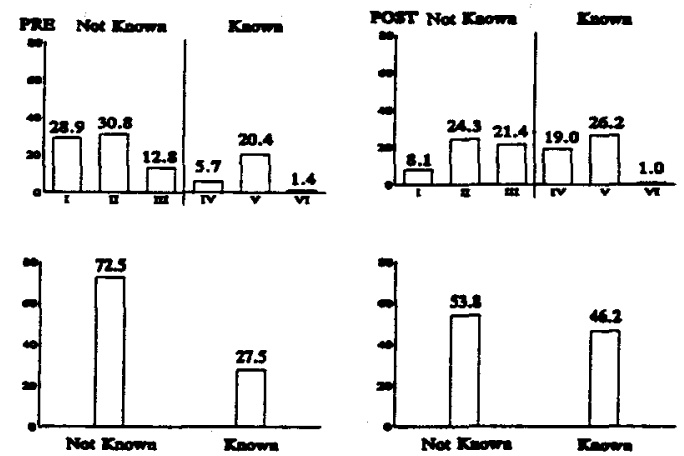
While these results suggest different patterns of gains for the two groups and stronger gains by the Comprehension-based class, there were no significant inter-group differences related to the Cloze and VKS vocabulary measures (Table 1 ).

\section{Grammar}

On the grammatical knowledge test, neither class showed significant gains in the ability to recognize correct or incorrect sentences. The Four-skill class, however, had significantly higher post-course than pre-course scores on the ability to correct incorrect sentences. Between-group differences were not significant.

Both groups made significant gains on the preposition test, but the gains of the Four-skill class were significantly greater than those of the Comprehension-based class. Thus while there is some evidence that grammatical knowledge is acquired in comprehensionbased courses without systematic grammatical instruction, instruction appears to lead to greater gains on these measures.

\section{INTROSPECTION TASK}

It was clear from student responses to the introspection task that their most common response to unknown words was to ignore them, unless understanding was specifically required to answer the comprehension questions after the reading task. Guessing the required meanings (sometimes with the help of the context in the comprehension questions as well as in the text) was the major strategy used with needed words. Some students reported looking in a dictionary - a strategy used more by certain individuals than others. All in all these findings suggested that students followed the "law of minimum effort" and that the nature of the comprehension questions determined to a large extent the extra mental effort they would make to find meanings of unknown vocabulary items.

\section{DISCUSSION}

The VKS results indicated that the Comprehension-based class made significant gains in knowledge of content words and discourse connectives relating to the instructed themes, whereas the Four-skill class demonstrated gains only on content words, and not on discourse connectives. (Both groups also made significant gains on the "total words" measure, mainly reflecting gains on content word knowledge.) These differential outcomes may reflect the greater focus in the Comprehension-based class on comprehension of the meaning of discourse chunks, which may reinforce (by making more 
salient) the learning of the meanings and functions of words related to text cohesion.

The VKS results further indicate that significant gains by the Comprehension-based class in knowledge of discourse connectives were only in relation to the instructed theme and not the uninstructed one; i.e., students were better able to provide the discourse connectives in the instructed text. This may simply be due to their better comprehension of the instructed text that facilitated their performing the task. Another possibility is that while discourse connectives are not theme specific, certain discourse connectives may be more characteristic of given text types (e.g., a scientific text may exhibit more cause and effect related discourse devices), and these text types may be associated more with certain themes. Replication of this finding and appropriate frequency counts for discourse connectives of interest in relation to all texts presented would be required for further interpretation.

The Comprehension-based class likewise made significant gains on the cloze test based on the instructed theme for total words, content words and discourse connectives, while on the uninstructed theme gains were only significant for content words. This may again suggest one way in which instruction makes a difference. Instructional focus on the content, organization and theme-related vocabulary of a given text, leading to better comprehension, appears to aid students in making a more successful choice of words for cloze blanks on the text at a later time when they no longer remember specific facts about the passage. The Four-skill class did not show significant gains on the discourse connectives, even though both classes spent approximately the same amount of time on the instructed theme. This probably reflected less focus and practice on text comprehension strategies. In spite of the different gain patterns for the two groups on vocabulary measures, inter-group differences were not significant.

Evidence was found for gains in grammatical knowledge (prepositions for both groups and grammatical correction skills for the Four-skill class). Comprehension-based class gains on knowledge of prepositions and discourse connectives provide evidence that some (lexically based) grammatical knowledge can be acquired incidentally through an exclusive focus on comprehending meaningful language without grammatical instruction. The considerable gains of the Comprehension-based class in knowledge of prepositions may be due to the fact that prepositions are structure/function words. It may be that emphasis on and consequent gains in text comprehension in the Comprehension- 
based class result in better understanding of the meaning and function of these words. However, superior gains of the Four-skill class suggest that explicit practice in the recognition and use of prepositions leads to a higher level of mastery.

There was no evidence of gains in grammaticality judgement (the ability to judge correct versus incorrect sentences) for either group. It is possible that both groups had indeed improved in this respect (i.e., implicit grammatical knowledge) but 1) due to the relatively high pre-course scores and the small number of sentences, change was not demonstrated statistically. On the other hand, the Fourskill class gained significantly on the ability to correct incorrect sentences, although group differences were not significant.

The fact that the Four-Skill class made gains on several grammatical measures (prepositions and error correction) suggests that explicit grammar teaching enhances students' ability to provide grammatically correct forms on tasks which draw their attention to these forms.

Preliminary results from the introspection study demonstrated that students tend to do the minimum required. Thus in comprehension exercises they seek or infer meaning of new words in reading texts only if this is necessary to answer the questions at the end. Our pedagogical conclusion is that the nature of the tasks students are required to do strongly influences what they will attend to, and should therefore be a very important consideration for classroom teachers.

\section{CONCLUSION}

Student gains on different measures based on the instructed (vs. the uninstructed) theme, as well as superior gains in grammatical knowledge for the comparison group clearly indicate that instruction makes a difference in the level of gains on different aspects of language knowledge. This conclusion is further supported by the introspection data indicating that the nature of instructional tasks affects what learners attend to and consequently may eventually learn.

The results of the study suggest superior gains by the Comprehension-based class in text comprehension and discourse processing, despite their lower level of gains in error correction (grammatical knowledge). It may be reasonable to conclude, therefore, that explicit grammar instruction is not needed for the improvement of text comprehension skills. At the same time, when learners are focused on meaning, they may not attend to grammatical forms, particularly those not required for global understanding, and may 
not, therefore, substantially improve their grammatical knowledge. The somewhat stronger results of the Four-skill class on grammatical measures suggest that learners benefit from some instruction focused on grammatical forms in order to develop sensitivity to them and possibly as a basis for greater accuracy in speaking and writing.

It appears that a comprehension-based program can achieve its instructional objectives in developing learners' receptive proficiency. Gains in other aspects of language are incidental and may exhibit idiosyncratic patterns among individual learners (e.g., some students may analyze formal aspects of language even though these are not a focus of instruction). A comprehension-based ESL program appears to be a viable instructional alternative in academic contexts where priority is accorded to the development of receptive skills for high level text and lecture comprehension, and may also be a solid preparation for moving into more form-focused instruction and productive use of the target language.

\section{NOTES}

1. We are very grateful to the following persons for their help with the project: Manko Rangongo, who taught the Four-skill class; Lise Duquette, who helped in the screening of French cognates for the vocabulary measures; Marie-Josée Vignola, Justine Foxall, Karina Fleck and Judith Holman, who were our research assistants at various stages, and Doreen Ready, our statistician. The School of Graduate Studies and Research and the Faculty of Arts, University of Ottawa, provided financial support.

2. An earlier report on this study was presented at the 9th World Congress of Applied Linguistics in Thessaloniki, Greece, in April 1990.

3. The linguistic composition of the classes was as follows: Comprehension-based $(\mathrm{N}=18)$ : 10 francophones, 5 Arabic speakers and 1 speaker each of Chinese, Spanish and Comorean; Four-skill $(\mathrm{N}=19)$ : 7 francophones, 4 Chinese speakers, 3 Polish speakers, 2 Arabic speakers and 1 speaker each of Japanese, Vietnamese and Mina.

4. The Anova $\mathrm{F}$ was .289; significance level .595. The Placement Test includes reading and listening sections with questions and activities based on authentic texts (e.g., dialogues, news stories, instructions, explanations, short reports, interviews or lectures). There are a variety of response formats including chart filling, short written answers, true or false and multiple choice. Questions test global comprehension of the text, as well as the ability to, for example, identify main and supporting ideas and to make inferences.

5. These are examples from the Grammatical Knowledge Test:

Correct: "Jade is a stone of high value."

"The cubs are generally born in the early spring."

Incorrect: "She speaks French very good."

"No two individuals are totally like each others."

6. These are examples of items of the preposition test:

"She has applied a new job."

"He is able to live very little money." 
7. The authors are continuing their research to refine this instrument and determine its applicability for different instructional and research contexts.

\section{THE AUTHORS}

T. Sima Paribakht is an Associate Professor in the Second Language Institute of the University of Ottawa. She teaches graduate and undergraduate courses in the Faculty of Education and the Department of Linguistics and ESL. She has contributed to the conceptualization, development of curriculum, implementation and ongoing evaluation of the University of Ottawa's comprehensionbased program. Dr. Paribakht has published a number of book chapters and articles and several books, and has co-edited several volumes of conference proceedings.

Marjorie Bingham Wesche is a Professor and former Director of the Second Language Institute of the University of Ottawa, where she teaches applied linguistics courses in the graduate programs of the Faculty of Education and Department of Linguistics. Dr. Wesche has published many research reports, book chapters and articles on language learning aptitude, adult classroom language learning, the linguistic environment of the language learner, French immersion programs and language testing. She co-edited Second Language Performance Testing (University of Ottawa Press, 1985), and is coauthor of Content-Based Second Language Instruction (Newbury House; Harper and Row, 1989).

\section{REFERENCES}

Allen, P., Carroll, S., Burtis, J. and Gaudino, V. (1987). The core French observation study. In B. Harley, P. Allen, J. Cummins \& M. Swain (Eds.), The Development of Bilingual Proficiency. Final Report. Vol. II: Classroom Treatment. Toronto: OISE.

Bialystok, E. (forthcoming). Achieving proficiency in a second language: a processing description. In R. Phillipson, E. Kellerman, L. Selinker, M. SharwoodSmith \& M. Swain (Eds.), Foreigu/Second Language Pedagogy Research: A commemorative Volume for Claus Faerch. Clevedon: Multilingual Matters.

Braidi, S. (1990). A theoretical framework for the interaction of input and syntactic principles and parameters in the formation of second language grammars. Ph.D. Dissertation, University of Delaware.

Burger, S. (1989). Content-based ESL in a sheltered psychology course: input, output and outcones. TESL Canada Joumal 6(2), 45-59.

Chaudron, C. (1985). Comprehension, comprehensibility and learning in the second language classroom. Studies in Second Language Acquisition 7, 216-232.

Chaudron, C. (1988a). Second Language Classrooms: Research in Teaching and Leaning. Cambridge: Cambridge University Press. 
Chaudron, C. (1988b). Intake: on models and methods for discovering learners' processing of input. Studies in Second Language Acquisition 7, 1-14.

Courchene, R. \& Pugh, B. (1986). A comprehension-based approach to curriculum design. Medium 11(2), 75-93.

Curtis, M. E. (1987). Vocabulary testing and vocabulary instruction. In M. G. McKeown \& M. E. Curtis (Eds.), The Nature of Vocabulany Acquisition (pp. 3751). Hillsdale, N.J.: Lawrence Erlbaum Associates.

Duquette, L. (1991). Étude sur l'apprentissage du vocabulaire en contexte en L2. Paper presented at the University of Ottawa, M.Ed. in Second Language Teaching Program.

Edwards, H. P., Wesche, M., Krashen, S., Clément, R. \& Kruidenier, B. (1984). Second language acquisition through subject-matter learning: a study of sheltered psychology classes at the University of Ottawa. The Canadian Modern Language Review 41(2), 268-282.

Ellis, R. (1992). Comprehension and the acquisition of grammatical competence in a second language. In R. Courchêne, J. Glidden, J. St-John \& C. Therien (Eds.), Comprehension-Based Second Language Teaching / L'enseignement des langues secondes axé sur la compréhension. Ottawa: University of Ottawa Press.

Faerch, C. \& Kasper, G. (1986). The role of comprehension in second language learning. Applied Linguistics 7(3), 257-274.

Faerch, C. \& Kasper, G. (Eds.) (1987). Introspection in Second Language Research. Clevedon, England: Multilingual Matters.

Genesee, F. (1987). Learning Through Two Languages. New York: Newbury House.

Harley, B. (1986). Second language proficiency and classroom treatment in early French inmersion. Paper presented at the FIFLV/Eurocentres Symposium on Error in Foreign Language Learning: Analysis and Treatment. London: Goldsmith's College, University of London.

Harley, B. (1992). Aspects of the oral proficiency of early immersion, late immersion and extended French students at grade 10. In R. Courchêne, J. Glidden, J. StJohn \& C. Thérien (Eds.), Comprehension-Based Second Language Teaching / L'enseignement des langues secondes axé sur la compréhension. Ottawa: University of Ottawa Press.

Hatch, E. (1983). Psycholinguistics: A Second Language Perspective. New York: Newbury House.

Hawkins, B. (1987). Scaffolded classroom interaction in a language minority setting Report, UCLA: Centre for Language Education and Research, Los Angeles.

Henzl, V. (1973). Linguistic register of foreign language instruction. Language Learning 23(2), 207-232.

Krashen, S. (1981). Second Language Acquisition and Second Language Leaming. Oxford: Pergamon.

Krashen, S. (1985). The Imput Hypothesis: Issues and Implications. New York: Longman.

Larsen-Freeman, D. \& Long, M. (1991). An Introduction to Second Language Acquisition Research. Longman: New York.

Lightbown, P. (1983). Acquiring English L2 in Quebec classrooms. In S. Felix, \& H. Wode (Eds.), Language Development at the Crossroads (pp. 101-120). GünterNarr Verlag.

Lightbown, P. (1992). Can they do it themselves? A comprehension-based ESL course for young children. In R. Courchêne, J. Glidden, J. St-John \& C. Thérien (Eds.), Comprehension-Based Second Language Teaching / L'enseignement des langues secondes axé sur la compréhension. Ottawa: University of Ottawa Press. 
Long, M. (1983). Linguistics and conversational adjustments to non-native speakers. Sudies in Second Language Acquisition 5, 177-193.

Long, M. (1985). Input and second language acquisition theory. In S. Gass \& C. Madden (Eds.), Input in Second Language Acquisition (pp. 377-393). Rowley, Mass.: Newbury House.

Neufeld, G. \& Schneiderman, E. (1980). Prosodic and articulatory features in adult language learning. In R. Scarcella \& S. Krashen (Eds.), Understanding Second and Foreign Language Leaming (pp. 15-33). New York: Newbury House.

Newmark, L. (1966). How not to interfere with language learning. Intemational Joumal of American Linguistics 32, 77-83.

Postovsky, V. (1974). Effects of delay in oral practice at the beginning of second language learning. Modem Language Joumal 58, 229-239.

Postovsky, V. (1981). The priority of aural comprehension in the language acquisition process. In H. Winitz (Ed.), The Comprehension Approach to Foreignt Language Instruction (pp. 170-186). New York: Newbury House.

Swaffar, J. (1986). Symposium on Comprehension-Based Language Teaching, videocassettes 1 and 2, Second Language Institute, University of Ottawa.

Swaffar, J. \& Stephens, D. (1981). What comprehension-based classes look and feel like in theory and practice. In H. Winitz (Ed.), The Comprehension Approach to Foreign Language Instriction (pp. 254-274). New York: Newbury House.

Swain, M. (1985). Communicative competence: some roles of comprehensible input and comprehensible output in its development. In S. Gass \& C. Madden (Eds.), Input in Second Language Acquisition (pp. 235-253). New York: Newbury House.

Swain, M. (1988). Manipulating and complementing content teaching to maximize second language learning. TESL Canada Joumal 6, 68-83.

Swain, M. \& Lapkin, S. (1982). Evaluating Bilingual Education: A Canadian Case Study. Clevedon: Multilingual Matters.

Terrell, T. (1982). The natural approach to language teaching: an update. Modem Language Journal 66(2), 121-132.

Van Patten, B. (1990). Attending to form and meaning in the input. Studies in Second Langtage Acquisition 12(3), 287-301.

Wagner-Gough, J. \& Hatch, E. (1975). The importance of input data in second language acquisition studies. Language Leaming 25(2), 297-308.

Wesche, M. (forthcoming). Input, interaction and acquisition: the linguistic environment of the second language learner. In C. Gallaway \& B. Richards (Eds.), Input and Interaction in Language Acquisition. Cambridge: Cambridge University Press.

Wesche, M. \& Ready, D. (1985). Foreigner talk in the university classroom. In S. Gass \& C. Madden (Eds.), Input in Second Language Acquisition (pp. 89-114). New York: Newbury House. 